\section{A PLEA FOR THE MATHEMATICIAN}

[At the request of the Editor, Professor Sylvester has furnished the following abridgment of his opening address to the Mathematical and Physical Section of the British Association at Exeter, with some supplemental notes appended in the course of its passing through the press.-ED.]

I.

$\mathrm{T}^{\mathrm{T}}$ is said of a great party leader and orator in the House of Lords that, when lately requested to make a speech at some religious or charitable meeting, he declined to do so on the ground that he could not speak unless he saw an adversary before him-somebody to attack or reply to. In obedience to a somewhat similar combative instinct, I set to myself the task of considering certain recent utterances of a most distinguished member of this Association, one whom I no less respect for his honesty and public spirit than I admire him for his genius and eloquence, but from whose opinions on a subject which he has not studied I feel constrained to differ. Göthe has said-

\section{"Verständige Leute kannst du irren sehn}

In Sachen nämlich, die sie nicht verstehn."

Understanding people you may see erring-in those things, to wit, which they do not understand.

I have no doubt that had my distinguished friend, the probable President-elect of the next Meeting of the Association, applied his uncommon powers of reasoning, induction, comparison, observation, and invention to the study of mathematical science, he would have become as great a mathematician as he is now a biologist; indeed he has given public evidence of his ability to grapple with the practical side of certain mathematical questions; but he has not made a study of mathematical science as such : and the eminence of his position and the weight justly attaching to his name, render it only the more imperative that any assertions proceeding from such a quarter, which may appear to be erroneous, or so expressed as to be conducive to error, should not remain unchallenged or be passed over in silence.

He says "mathematical training is almost purely deductive. The mathematician starts with a few simple propositions, the proof of which is so obvious that they are called self-evident, and the rest of his work consists of subtle deductions from them. The teaching of languages, at any rate as ordinarily practised, is of the same general nature-authority and tradition furnish the data, and the mental operations are deductive." It would seem from this that, according to Prof. Huxley, the business of the mathematical student is from a limited number of propositions (bottled up and labelled ready for future use) to declare any required result by a process of the same general nature as a student of language employs in declining and conjugating his nouns and verbs: that to make out a mathematical proposition and to construe or parse a sentence are equivalent or identical mental operations. Such an opinion scarcely seems to need serious refutation. The passage is taken from an article in Macmillan's Magazine for June last, entitled "Scientific Education-Notes of an After-dinner Speech," and I cannot but think would have been couched in more guarded terms by my distinguished friend had his speech been made before dinner instead of after.

The notion that mathematical truth rests on the narrow basis of a limited number of elementary propositions, from which all others are to be derived by a process of logical inference and verbal deduction, has been stated still more strongly and explicitly by the same eminent writer in an article of even date with the preceding, in the Fortnightly Review, where we are told that "Mathematics is that study which knows nothing of observation, nothing of experiment, nothing of induction, nothing of causation." I think no statement could have been made more opposite to the facts of the case: that mathematical analysis is constantly invoking the aid of new principles, new ideas, and new methods, not capable of being defined by any form of words, but springing direct from the inherent powers and activity of the human mind, and from continually renewed introspection of that inner world of thought of which the phenomena are as varied and require as close attention to discern as those of the outer physical world-to which the inner one in each individual man may, I think, be conceived to stand in somewhat the same general relation of correspondence as a shadow to the object from which it is projected, or as the hollow palm of one hand to the close fist which it grasps of the other: that it is unceasingly calling forth the faculties of observation and comparison, that one of its principal weapons is.induction, that it has frequent recourse to experimental trial and verification, and that it affords a boundless scope for the exercise of the highest efforts of imagination and invention.*

Lagrange, than whom no greater authority could be quoted, has expressed emphatically his belief in the importance to the mathematician of the faculty of observation : t Gauss has called mathematics a science of the

* The annexed instance of Mathematical Euristic is, I think, from its intrinsic interest, worthy of being put on record. The so-called canonical representation of a binary quartic of the eighth degree I found to be a quartic multiplied by itself, together with a sum of powers of its linear factors, just as for the fourth degree it was known to be a quadric into itself, together with a sum of powers of its factors: but for a sextic a cubic multiplied into itself, with a tail of powers as before, was not found to answer. To find the true representation was like looking out into universal space for a planet desiderated according to Bode's or any other empirical law. I found my desideratum as follows: I invented a catena of morphological processes which, applied to a quadric or to a quartic, causes each to reproduce itself: I then considered the two quadrics and two quartics to be noumenally distinguishable (one as an auto-morphic derivative of the other), although phenomenally identical. The same catena of processes applied to the cubic gave no longer an identical but a distinct derivative, and the product of the two I regarded as the analogue of the before-mentioned square of the quadric or of the quartic. This product of a cubic by its derivative so obtained together with a sum of powers of linear factors of the original cubic, $I$ found by actual trial to my great satisfaction satisfied the conditions of canonicity, and it was thus I was led up to the desired representation which will be found reproduced in one of Prof. Cayley's memoirs on Quantics and in Dr. Salmon's lectures on Modern Algebra. Here certainly induction, observation, invention, and experimental verification all played their part in contributing to the solution of the problem. I discovered and developed the whole theory of canonical binary forms for odd degrees, and, as far as yet made out, for even degrees too, at one evening sitting, with a decanter of port wine to sustain nature's flagging energies, in a back office in Lincoln's-Inn-Fields. The work was done, and well done, but at the usual cost of racking thought-a brain on fire, and feet feeling, or feelingless, as if plunged in an ice pail. That zight zue slept no more. The canonisant of the quartic (its cubic covariant) was the first thing to offer itself in the inquiry. I had but to think the words "Resultant of Quintic and its Canonisant," and the octodecadic skew invariant would have fallen spontaneously into my lap. By quite another mode of consideration $M$. Hermite subsequently was led to the discovery of this, the key to the innermost sanctuary of Invariants - so hard is it in Euristic to see what lies immediately before one's eyes. The disappointment weighed deeply, far too deeply, on my mind, and caused me to relinquish for long years a cherished field of meditation: but the whirligig of time brings about its revenges. Ten years later this same canonisant gave me the upper hand of my honoured predecessor and givide, M. Hermite, in the inquiry (referred to at the end of this address) concerning the invariantive criteria of the constitution of a quintic with regard to the real and imaginary. By its aid I discovered the essential character of the famous amphigenous surface of the ninth order, and its bicuspidal universal section of the fourth order (otherwise termed the Bicorn), as may be seen in the third part of my Triology, printed in the Philosophical Transactions.

+ I was under the conviction that a passage to that effect from Lagrange had been cited to me some years ago by $M$. Hermite of the Institute of France; on applying to him on the subject, I received the following reply: 'Relativement à l'opinion que suivant vous j'aurais attribuee à Lagrange, je m'empresse de vous informer qu'il ne faut aucunement, a ma connaissance, 'en rendre responsable. Nous nous sommes entretenus du rôle de la facultè d"observation dans les Etudes que nous avons pourswivies de concert pendant bien des années, et c'est alors, sans doute, que je vous aurai conté une anecdote que je tiens de M. Chevreul. M. Chevreul, allant a l'Institut dans la voiture de Lagrange, a été vivement frappé du sentiment de plaisir avec lequel ce grand gémetre lui faisait voir, dans un travail manuscrit, la beauté extérieure et artistique, si je peux dire, des nombreuses formules qui y figuraient. Ce sentiment nous lavons tous éprouvé en faisant, ave sincérité, abstraction de lidée analytique dont les formules sont lexpression écrite. Il y a là, n'est-il point vrai, un imperceptible lien qui rattache au monde de l'art le monde abstrait de l'algèbre et de l'analyse, et j'oserai même vous dire que je crois a des sympathies reelles, qui vous font trouver un charme, dans les notations d'un auteur, et da

dun autre, par lapparence seule des formules. 1 am, however, none the less persuaded that on one or more than one occasion, M. Hermite, speaking of Lagrange, expressed to me, "f that the supposed on Lagrange s, then certainly on his own high authority, "that the faculty of observation was no less necessary for the 
eye, and in conformity with this view always paid the most punctilious attention to preserve his text free from typographical errors : the ever to be lamented Riemann has written a thesis to show that the basis of our conception of space is purely empirical, and our knowledge of its laws the result of observation; that other kinds of space might be conceived to exist, subject to laws different from those which govern the actual space in which we are immersed; and that there is no evidence of these laws extending to the ultimate infinitesimal elements of which space is composed. Like his master Gauss, Riemann refuses to accept Kant's doctrine of space being a form of intuition,* and regards it as possessed of physical and objective reality. I may mention that Baron Sartorius von Waltershausen (a member of this Association), in his biography of Gauss ("Gauss zu gedächtniss"), published shortly after his death, relates that this great man was used to say that he had laid aside several questions which he had treated analytically, and hoped to apply to them geometrical methods in a future state of existence, when his conceptions of space should have become amplified and extended; for as we can conceive beings (like infinitely attenuated book-worms in an infinitely thin sheet of paper) which possess only the notion of space of two dimensions, so we may imagine beings capable of realising space of four or a greater number of dimensions. $\dagger$ Our Cayley, the central luminary, the Darwin of the English school of mathematicians, started and elaborated at an early age, and with happy consequences, the same bold hypothesis.

Most, if not all, of the great ideas of modern mathematics have had their origin in observation. Take, for instance, the arithmetical theory of forms, of which the foundation was laid in the diophantine theorems of Fermat, left without proof by their author, which resisted all the efforts of the myriad-minded Euler to reduce to demonstration, and only yielded up their cause of being when turned over in the blowpipe flame of Gauss's transcendent genius; or the doctrine of double periodicity, which resulted from the

* It is very common, not to say universal, with English writers, even such authorised ones as Whewell, Lewes, or Herbert Spencer, to refer to Xant's doctrine as affrming space "to be a form of thought," or "of the understanding." This is putting into Kant's mouth (as pointed out to me by Dr. C. M. Ingleby), words which he would have been the first to disclaim, and is as inaccurate a form of expression as to speak of "the plane of a sphere," meaning at a meeting of the Royal Society. Wh long ago I heard a famous naturalist do leading doctrines in a succinct form, weighty with thought, and free from all impertinent comment, should study Schwegler's Handbook of Philom all impertinent comment, should study Schwegler's Handbook of Philosophy, of Aristotle's doctrine of matter and form, showing how matter passes un ceasingly upwards into form, and form downwards into matter ; which wil remind many of the readers of NATURE of the chain of depolarisations wh remind many of the readers of NATURE of the chain of depolarisations and repolarisations which are supposed to explain the decomposition of water under galvanic action, eventuating in oxygen being thrown off at one pol and hydrogen at the other (it recalis also the high algebraical theories in which the same symbols play the part of operands to their antecedents an operators to their consequents): at one end of the Aristotelian chain come out $\pi \rho \omega \tau \eta \eta \lambda \eta$, at the other, $\pi \rho \tilde{\omega}$ тuv eidos. We have, then, only to accept and apply the familiar mathematical principle of the two ends of infinity being on and the same point, and the otherwise immoveable stumblingblock of duality is done away with, and the universe reintegrated in the wished-for unity. Fo this corollary, which to many will appeat fanciful, neither Aristotle nor Schwegler is responsible. We perfectly understand how in perspective the latent polarities of any point in a closed curve (taken as the object) may be developed into and displayed in the form of a duad of quasi points at an infinit distance from each other in the picture. In like manner we conceive how actuality and potentiality which exist indistinguishably as one in the absolute may be projected into seemingly separate elements or moments on the plane of the human understanding. Whatever may be the merits of the theory in not have anticipated, and to accomplish what Aristotle attempted but not have anty failed to effect, viz. the complete subversion of the "Platonic avowedly failed to effect, viz. the complete subversion of

$t I t$ is well known to those who have gone into these views, that the laws of motion accepted as a fact suffice to prove in a general way that the space we live in is a flat or level space (a "homaloid"), our existence therein being assimilable to the life of the bookworm in a flat page : but what if the page should be undergoing a process of gradual bending into a curved form? to the possibility of our being able to infer, from certain unexplained pheno. to the possibility of our being able to infer, from certain unexplained phenomena of light and magnetism, thie fact of our level space of three dimensions
being in the act of undergoing in space of four dimensions (space as inconceivable to us as our space to the supposititious bookworm) a distortion analogous to the rumpling of the page. I know there are many, who, like my honoured and deeply lamented friend the late eminent Prof. Donkin, regard observation by Jacobi of a purely analytical fact of transformation ; or Legendre's law of reciprocity; or Sturm's theorem about the roots of equations, which, as he informed me with his own lips, stared him in the face in the midst of some mechanical investigations connected (if my memory serves me right) with the motion of compound pendulums; or Huyghen's method of continued fractions, characterised by Lagrange as one of the principal discoveries of "that great mathematician, and to which he appears to have been led by the construction of his "Planetary Automaton ;" or the new algebra, speaking of which one of my predecessors (Mr. Spottiswoode) has said, not without just reason and authority, from this chair, "that it reaches out and indissolubly connects itself each year with fresh branches of mathematics, that the theory of equations has almost become new through it, algebraic geometry transfigured in its light, that the calculus of variations, molecular physics, and mechanics" (he might, if speaking at the present moment, go on to add the theory of elasticity and the developments of the integral calculus) "have ail felt its influence."

Now this gigantic outcome of modern analytical thought, itself, too, only the precursor and progenitor of a future still more heaven-reaching theory, which will comprise a complete study of the interoperation, the actions and reactions, of algebraic forms (Analytical Morphology. in its absolute sense), how did this originate? In the accidental observation by Eisenstein, some twenty or more years ago, of a single invariant (the Quadrinvariant of a Binary Quartic) which he met with in the course of certain researches just as accidentally and unexpectedly as $M$. Du Chaillu might meet a Gorilla in the country of the Fantees, or any one of us in London a White Polar Bear. escaped from the Zoological Gardens. Fortunately, he pounced down upon his prey and preserved it for the contemplation and study of future mathematicians. It occupies only part of a page in his collected posthumous works. This single result of observation (as well entitled to be so called as the discovery of Globigerinæ in chalk

the alleged notion of generalised space as only a disguised form of algebraical formulisation; but the same might be said with equal truth of our notion of infinity in algebra, or of impossible lines, or lines making a zero anglc in geometry, the utility of dealing with or lines making a zero ang. notions no one will be found ealing with which as positive substantiated Chasles' theory of be found to dispute. Dr. Salmon, in his extensions of of probability (published in the $E$ dustics to surfaces, Mr. Clifford, in a question of partitions, and also in $m y$ Educational Times), and myself in my theory sophical Marazine also in my paper on Burycentric Projection in the Philo handling space of four dimelt and given evidence of the practical utility of over, it should be our dimensions, as if it were conceivable space. More figured space of four dimensions is that every perspective representation of figured space of four dimensions is a figure in real space, and that the pro perties of figures admit of being studied to a great extent, if not completely, in their perspective representations. In philosophy, as in æsthetic, the highes knowledge comes by faith. I know (from personal experience of the fact) that Mr. Linnell can distinguish purple tints in clouds where my untutored eye and unpurged vision can perceive only confused grey. If an Aristotle or Descartes, or Kant assures me that he recognises God in the conscience, accuse my own blindness if I fail to see with him. If Gauss, Cayley, Riemann, Schalfi, Salmon, Clifford, Krönecker, have an inner assurance of the reality of transcendental space, I strive to bring my faculties of mental vision into accordance with theirs. The positive evidence in such cases is more worthy than the negative, and actuality is not cancelled or balanced by privation, as matter plus space is none the less matter. I acknowledge two separate sources of authority-the collective sense of mankind, and the illumination of privileged intellects. As a parallel case, I would ask whether it is by demonstrative processes that the doctrine of limits and of infinitely greats and smalls, has found its way to the ready acceptance of the multitude; or whether, after deducting . whatever may be due to modified hereditary cerebral organisation, it is not a consequence rather of the insensible moulding of the ideas under the influence of language which has become permeated with the notions originating in the minds of a few great thinkers? I am assured that Germans even of the non-literary classes, such as ladies of fashion and novel readers, are often appalled by the habitude of their English friends in muddling up together, as if they were nearly or quite the same thing, the reason and the understanding in doing into English the words Vernunft and Verstand, thereby confounding distinctions now become familiar (such is the force of language) to the very milkmaids of Fatherland. As a public teacher of mere striplings, I am often amazed by the facility and absence of resistance with which the principles of the infinitesimal calculus are accepted and assimilated by the present race of learners. When I was young, a boy of sixteen or seventeen who knew his infinitesimal calculus would have been almost pointed at in the streets as a prodigy, like Dante, as a man who had seen hell. Now-a-days, our Woolwich cadets at the same age talk with glee of asymptotes and points of contrary flexure, and discuss questions of double maxima and minima, or ballistic pendulums, or motion in a resisting medium, under the familiar and ignoble name of sums. 
or of the Confoco-ellipsoidal structure of the shells of the Foraminifera), which remained infructuous in the hands of its distinguished author, has served to set in motion a train of thought and propagated an impulse which have led to a complete revolution in the whole aspect of modern analysis, and will continue to be felt until Mathematics are forgotten and British Associations meet no more.

\section{J. J. SYLVESTER}

\section{TECHNICAL EDUCATION}

MANCHESTER at all events is beginning to be alive $\mathrm{I}$ to the present situation, and at a meeting on the I 8 th inst., the following document, expressing the views of the Council of the Society of Arts, was read.

I. The Council of the Society of Arts have received a communication from Owens College Extension Committee, Manchester, asking their co-operation in the extension of technical education, or, more properly, Scientific Instruction; and it affords them much pleasure to do whatever lies in their power to advance this important national object. With this view, the Council have invited the members of the Society, and especially those resident in the locality, as well as the authorities of Owens College, to meet them in conference on the subject, to discuss the best means by which scientific instruction may be promoted, and to establish an organisation which will keep an influence at work to accomplish what is so urgently needed.

2. The necessity and importance of improved scientific instruction for the people of the United Kingdom, in order that they may be placed in a favourable position in the race of industrial competition with other nations, has, for some time past, been forced upon the notice of the Society of Arts, whose chartered objects are the Promotion of Arts, Manufactures, and Commerce.

3. The great international displays of industry in $185 \mathrm{I}, 1855$, I862, and I867, have shown unmistakeably that, if this country is to maintain her position as a commercial and manufacturing power, the people (and in this term are comprehended not only artisans, but also persons of higher position in the social scale must have at their command the means of education improved in its general character, and embracing, if not based upon, science to a far greater extent than has hitherto been the case. The official jury reports at all the exhibitions abound in declarations of this character, and the country can no longer afford to ignore the fact, but must earnestly set to work to bring about a change. These reports, as well as those of the artisans who were sent to the Paris Exhibition of 1867 by the Society, on and all point out the great educational facilities which are avail able for all classes, and especially the artisan class, upon the Continent.

4. The Council are of opinion that existing schools and colleges, where science has hitherto been all but excluded, should adopt some means for its being taught; and that where such teaching already exists, measures should be taken for extending the usefulness of the institutions, and rendering them more easy of access to the great body of the people; whilst in localities where no such facilities exist, means should be taken to secure their foundation. The localities must themselves stir in this reform, and their efforts should be aided by pecuniary assistance and countenance by the State.

5. The nation must set itself earnestly to work to bring about the sought-for change in the education of the people. The evils have been so often pointed out, that it is unnecessary to enter into detail ; our duty is to supply the remedy. This the Council believe to be by the localities setting themselves heartily to work, and when they have shown themselves in earnest by raising funds and organising establishments for the teaching - of science, they should be entitled, as of right, to aid from the State.

6. In order, however, that such establishments, colleges, or schools should be of value to the mass of the people, so that they can take advantage of the facilities which would then be offered to them, it is absolutely necessary that elementary education, commonly known as primary education, should be extended far more widely than at present. To an ignorant population the establishment of colleges and schools for the teaching of science will be of little avail, and unless the blessings of an ordinary elementary education, i.e., reading, writing, and arith- metic, at least, can be more diffused, so as to place oul people on a par with those of Switzerland, Prussia, Saxony, \&c., the attempt to extend the teaching of science will be in vain. Again, not only must we have improved elementary education, but these elements must themselves be taught by improved methods and organisation, so that less time may be occupied in acquiring them, thus leaving free for the learning of elementary science some of those years which are now unnecessarily taken up in mastering the mere rudiments of knowledge. Abroad it is the custom of the State only to deal with this and many other matters of public concern, but such is not the case here. The Council do not recommend State interference as of choice, but of necessity. This work of education must be done, and will have to be done, wholly by Government, if not otherwise. Experience proves that it can be done by a combination of voluntary efforts with Government aid, as in the existing system of primary education, and in the instruction aided by the Science and Art Department. The Council think that the work is to be done in part nationally, in part voluntarily, but not upon a haphazard system.

7. Adam Smith, the earliest, and, perhaps, the first English writer on political economy, as well as Mr. J. Stuart Mill, its present most able exponent, recommend scientific instruction as profitable to the nation. Her Majesty's Government must not plead economy as an excuse, for the highest and wisest economy comes out of wise expenditure.

8. The Council believe that this is the feeling of the country, which the Government will regard with respectful attention. Government must be urged to co-operate with Owens College and other bodies, either existing or to be established. Parliamentary grants are now made to the old universities of England and Scotland, and to the Queen's Colleges in Ireland, and there is no reason why the same principle should not be extended, and grants made to modern educational establishments in the great centres of industry. The Council are of opinion that a Government resulting from a wide representation of the whole people ought adequately to represent the highest intelligence and aspirations of that people for improvement, and not limit its responsibility and its labours to matters of police. There can be no more profitable investment of national capital drawn from taxes paid by the whole nation, than in promoting the best education among all classes of the people, and the widest extension of sound knowledge, on which the Arts, Manufactures, and Commerce of a kingdom rest.

At the meeting, the following resolution, proposed by Professor Jack, was carried unanimously :-

"That the best interests of the country demand the establishment of a complete system of primary education, the extension of the system of science classes under a responsible department of the Government, and under a definite plan, and especially the establishment of Science Colleges in the principal industrial centres of the United Kingdom : and such colleges ought to be established and maintained partly by local efforts, and partly by liberal assistance from the State; and existing institutions stuch as Owens College ought to be made available for the purpose."

For the present, we content ourselves with chronicling these facts, and calling upon other centres of industry, such as Birmingham, to help to bring the pressure of public opinion to bear upon the members of the Government, who, perhaps, more than anyone else, require to be taught the vital importance of technical education to the future national life.

\section{WHENCE COME METEORITES?}

$\mathrm{N}$ examining a mass of meteoric iron found in the 1 Cordillera of Deesa (Chili), M. Stanislas Meunier, of the Museum of Natural History in Paris, has discovered evidences of an unexpected relationship between this iron and two meteorites fallen at a great distance from Chili; viz. a mass of iron found at Caille (Alpes Maritimes), and a stone which fell at Sétif (Algeria) June 9, I 867.

The meteorite of Deesa is a mixture of these two rocks: it is composed of iron which is identical with that of Caille, injected in a state of fusion into a stone which is identical with that of Sétif. The iron of Deesa is thus evidently an eruptive rock, and it is the first hitherto 